\title{
Determining the Level of Nurses' Compliance with the Isolation Precautions Taken for Preventing Healthcare Associated Infections
}

\author{
Kevser Tanyeri' (D), Burçin Ișık² (1) \\ 'Departmen of Orthopedics and Traumatology, Lütfi Kırdar Training and Research Hospital, İstanbul, Turkey \\ 2Department of Nursing, Gaziantep Islam Science and Technology University, Faculty of Health Sciences, Gaziantep, Turkey
}

ORCID iDs of the authors: K.T. 0000-0002-6048-126X; B.I. 0000-0002-5469-017X.

Cite this article as: Tanyeri K, Ișı B. Determining the Level of Nurses' Compliance with the Isolation Precautions Taken for Preventing Healthcare Associated Infections. Cyprus J Med Sci 202I; 6(I): 86-92.

\section{BACKGROUND/AIMS}

Healthcare-associated infections (HAls) are a major issue in hospitals worldwide. Isolation precautions are considered necessary to reduce the spread of HAls. The failure of nurses to comply with isolation precautions may have a negative impact on both nursing care and the psychological and social lives of patients and their families. Therefore, this study aims to identify the level of nurse compliance with isolation precautions taken to prevent HAls and to develop suggestions in line with the results obtained.

\section{MATERIAL and METHODS}

This work consisted of a cross-sectional descriptive study. The study population was 180 nurses working in a private hospital in Nicosia, the Turkish Republic of Northern Cyprus. Although it aimed to reach the entire population, the study sample consisted of II0 nurses. Data were collected between May and June 2017, using an Information Form and the Compliance with Isolation Precautions Scale.

\section{RESULTS}

Nearly all the nurses had adequate knowledge about HAls and isolation precautions. The study results showed that nurses had a high level of compliance with isolation precautions for preventing hospital infections.

\section{CONCLUSION}

These results suggest that it may be advisable to increase the number of continuous education programs that encourage nurses and healthcare professionals to comply with infection control measures and isolation precautions at the highest level and to raise their awareness about the importance of hand hygiene habits and immunization against HAls.

Keywords: Nurse, infection, healthcare, prevention, isolation, compliance

\section{INTRODUCTION}

The Centers for Disease Control and Prevention (CDC) and the World Health Organization define healthcare-associated infections (HAls) as the most important source of mortality and morbidity worldwide (I, 2). The term HAls is often used to define hospital or healthcare-related infections and is described through phrases, such as hospital-acquired infection or hospital infection (3). HAls negatively affect the recovery of patients who are hospitalized or have received treatment in a hospital, and may lead to an increase in morbidity and mortality rates, cause epidemics, and place additional financial burden on both patients and governments (4-8). These infections pose an serious problem for the effective provision of modern hospital services. The rate of hospital infections is considered one of the most important indicators of hospital quality. Furthermore, the prevention and control of the development of infection are among the issues that are increasingly important within the framework of patient safety (9).

HAls are defined as infections that develop after admission to a hospital, were not in an incubation period at the time of admission, or that sometimes occur after discharge despite having developed in a hospital. They usually occur 48-72 hours after hospitalization and within 10 days of discharge $(6,10)$. HAls-of which there is a greater than $10 \%$ incidence, particularly in multi-bed large hospitals-prolong hospital stay; increase medical costs by requiring additional treatment interventions; cause loss of labor and productivity; decrease quality of life; and increase disease types, emotional stress, drug use, functional disorders, and mortality rates (II, I2). 
One of the main strategies to control HAls is to take isolation precautions. Isolation precautions are preventive methods defined as "the prevention of transmission of microorganisms from infected patients to other patients, visitors and healthcare personnel, the separation of individuals with infectious diseases for protective purposes and the restriction on their movements" (13-15). The isolation precautions taken for preventing HAls are applied as standard measures (handwashing; use of gloves, hand antiseptics, aprons, and face protectors; sterilization and disinfection, medical waste management, and environmental control) and measures against modes of transmission (tight contact isolation; droplet isolation measures; and the use of face protectors, aprons, gloves, and hand sanitizer) $(5,6,8,16)$. Isolation precautions are widely applied in many health institutions and considered necessary to reduce the spread of HAls (17). Compliance with the infection control measures set by the CDC has a significant effect on the prevention of HAls, and healthcare professionals implementing these measures reduce the incidence of these infections by $30 \%$ (I). Rosenthal et al. (8) reported that the rate of HAls significantly decreased only by adapting to hand hygiene practices. Contrary to this, the failure of healthcare professionals to comply with all infection control measures has also been found to negatively affect the quality of patient care and safety, increasing the risk of morbidity and mortality (6). Studies conducted in Turkey report that HAls cause a significant additional budget cost, prolonging the length of hospital stay by 4.3-33.5 days, and nurses allocate an additional 28.73 minutes to patients who develop HAls $(12,18)$.

The failure of nurse to comply with isolation precautions may have a negative impact on both nursing care and psychologi-

\section{Main Points:}

- With regard to patient safety, healthcare-associated infections (HAls) are the most common global health problem, and their consequences may be related to morbidity, mortality, prolonged hospitalization, and negative effects on the economic welfare of patients and nations. Therefore, health managers and government policies and interventions should pay greater attention to this subject. This study provides valuable data about nurses' knowledge, skills, and attitude regarding the isolation precautions taken to prevent HAls.

- Our findings highlight the importance of isolation precautions taken to prevent HAls. They have implications for nurses worldwide who are responsible for taking care of patients while using infection prevention practices.

- Management departments of hospitals should strive to create an organizational atmosphere in which adherence to the recommended isolation precautions taken to prevent HAls is considered an integral part of providing high-quality care.

- Modern-day understanding treats hospital infections as a patient safety and public health problem. If hospitals seek to reduce infection rates, they must create awareness about the importance of isolation precautions and develop/implement innovative continuous and motivational programs according to the needs of all healthcare professionals. cal and social lives of patients and their families (17). In previous studies, the factors that prevent nurses' compliance with standard isolation measures are defined as follows: emergencies, lack of equipment, negative effects of protective materials, patients' discomfort with healthcare professionals wearing masks and aprons, lack of commitment from institutional management, heavy workloads, low number of nurses, the time needed to fully comply with guidelines, effects of protective equipment on physical appearance, professional knowledge and experience, nurses thinking that nothing would happen to them, negative role modeling from head nurses at clinics, and being influenced by the working style of physicians who do not obey the rules $(14,16,19)$. It is extremely important, in terms of providing safe and qualified healthcare, that nurses-who spend a lot of time with patients, establish close relationships during the care process, and are responsible for patient care processes-comply with infection control measures (20). Therefore, this study determined the importance of the level of nurse compliance with isolation precautions taken to prevent HAls, developed suggestions by determining the factors affecting nurse compliance, and created resources meant particularly for health institutions and organizations.

\section{MATERIALS and METHODS}

\section{Design and Sampling}

This work was planned as a cross-sectional descriptive study. The study population consisted of 180 nurses working in a private hospital in Nicosia, the Turkish Republic of Northern Cyprus. Although it aimed to reach the whole population, the final study sample consisted of II0 nurses because 25 nurses were on leave and 45 nurses did not volunteer to participate in the research. In the study, $61.1 \%$ of the targeted population was reached.

\section{Data Procedure and Instruments}

Data were collected between May and June 2017 using an Information Form and the Compliance with Isolation Precautions Scale (CIPS). The Information Form, prepared by the researchers considering related literature, consisted of questions about the sociodemographic characteristics of the nurses and questions on whether they received any training on the isolation precautions taken to prevent HAls, had adequate knowledge about HAls, had been immunized against HAls, and whether they and other hospital personnel complied with the isolation precautions taken to prevent HAls $(5,10,13,15,20,22,26,28)$. The CIPS was developed by Tayran and Ulupınar (I3) to determine the level of nurse compliance with the isolation precautions; validity and reliability studies were conducted on it, and the Cronbach's alpha reliability coefficient was found to be 0.85 . In this study, the Cronbach's alpha reliability coefficient of the scale was found to be 0.91 . The scale is a five-point Likert-type scale consisting of 18 items and the following 4 factors: route of infection (items $3,8,9,10$, and II), practitioner-patient safety (items $2,5,12,14,16$, and 17), environmental safety (items I, 13, 15, and 18 ), and hand hygiene/glove use (items 4,6 , and 7 ). Items $5,7,12$, and 17 were scored in reverse. The lowest and highest scores on the scale are 18 and 90, respectively. Higher scores indicate better the compliance with isolation precautions (I3).

\section{Ethical Considerations}

The approval and permission necessary to conduct the study were obtained from the hospital and ethics committee (YDU/2017/47-4II). The nurses who voluntarily accepted to par- 
ticipate in the study signed a consent form after they were informed about the purpose of the study and the confidentiality of the records.

\section{Statistical Analysis}

The data were evaluated using the Statistical Package for the Social Sciences 24.0 statistical analysis program (IBM SPSS Corp.; Armonk, NY, USA) and descriptive statistics (arithmetic mean, standard deviation, frequency, and percentage). The Kolmogorov-Smirnov and Shapiro-Wilk tests were used to determine whether the data were normally distributed. The independent sample $t$-, Mann-Whitney $U$, and Kruskal-Wallis tests were used to determine the significance of the differences between the groups (2I).

\section{RESULTS}

The mean age of the nurses who participated in the study was $30.54 \pm 9.87$, and $40.91 \%(n=45)$ were $\leq 25$ years of age. A total of $82.73 \%$ of the nurses ( $n=91)$ were female, $59.09 \%(n=65)$ were single, $66.37 \%$ ( $n=73$ ) had no children, $79.09 \%$ ( $n=87$ ) had a Bachelor's or Master's degree, $85.45 \%$ ( $n=94)$ worked as a nurse, and $41.82 \%$ $(n=46)$ had professional experience of $\geq 6$ years. The mean working experience was $7.59 \pm 8.94$ years. In addition, $94.55 \%$ of the nurses $(n=104)$ received training on isolation precautions and $53.85 \%$ $(n=56)$ received this training from an infection control nurse. A total of $91.82 \%$ of the nurses $(n=|0|)$ had adequate knowledge about HAls and isolation precautions, $68.18 \%(n=75)$ thought HAls could be controlled through training, and $93.64 \%(n=103)$ emphasized that hand hygiene was important in preventing infections. Furthermore, $66.36 \%$ of the nurses ( $n=73$ ) were not immunized against HAls; only $33.64 \%(n=37)$ were. A total of $54.06 \%(n=20)$ and $2.70 \%(n=1)$ of the nurses who were immunized against HAls had anti-hepatitis $B$ virus (HBV) and anti-human immunodeficiency virus vaccines, respectively; however, $43.24 \%$ of the nurses ( $n=16$ ) who were immunized against HAls did not respond to the question on immunization. Finally, $79.09 \%$ of the nurses $(n=87)$ stated that healthcare personnel influenced the development and spread of HAls and $50.91 \%(n=56)$ reported that hospital employees did not adequately comply with isolation precautions (Table I).

The nurses' total mean score on the CIPS was 3.75 \pm 1.01 . The nurses definitely agreed with 14 items but definitely disagreed with four items. The nurses received the highest scores on the items "If the patient undergoing isolation is examined in another unit, I would warn the relevant unit supervisor to continue to apply the isolation precautions." (4.45 \pm l.02) and "I wash my hands before contact with the patient." (4.42 \pm I.17). The nurses received the lowest scores on the items of "I do not need to wash or scrub my hands when I remove gloves." (I.84 \pm 1.19$)$ and "I do not mind touching a wound of the patient with naked hands." (I.58 \pm 1.24$)$. The nurses' total mean score indicates that they have a high level of compliance with isolation precautions (Table 2).

The mean CIPS score of nurses who received training on the isolation precautions taken to prevent HAls was 76.81 \pm 14.99 , whereas those without such training had a mean score of $62.50 \pm 15.64$, which was a statistically significant difference $(p \leq .05)$ in favor of those with the training (Table 3).

The mean CIPS score of the nurses who having adequate knowledge about isolation precautions taken to prevent HAls was $77.35 \pm 14.42$, whereas those without such knowledge had a mean

score of $61.22 \pm 17.98$; this is a statistically significant difference $(p \leq .01)$ in favor of those with adequate knowledge (Table 3).

The mean CIPS score of the nurses who believed that HAls could be controlled by giving relevant training was 78.7I \pm 13.64 , whereas the mean score of those who did not believe that HAls can be controlled in this manner was $51.88 \pm 17.63$, indicating a statistically significant difference between the mean scores $(p \leq .01)$ in favor of the former (Table 3).

The mean CIPS score of the nurses who were immunized against HAls was $70.78 \pm 18.14$, whereas the mean score of those who

TABLE I. Nurses' Training and Immunization Status Regarding HAls
and Isolation Precautions ( $n=\| 0$ )

Training and immunization

n

$\%$

Being trained on isolation precautions

Yes

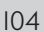

94.55

No

5.45

Trainer/training place (n:I04)

Infection control nurse

56

In-service training

$15 \quad 14.42$

Undergraduate education

26

Congress/Symposium

7

25.00

Having adequate knowledge about HAls

Yes

101

91.82

No

Whether HAls can be controlled through training

Yes

75

68.18

No

Partially

8

7.27

Whether hand hygiene is important in preventing HAls

Yes

No

Partially 24.55

Immunization

Yes

No

Immunization type (n:37)

No response

16

Anti HBV

20

Anti HIV

Whether healthcare personnel affect the development and spread of HAls Yes

No

I 0.91

Partially

$22 \quad 20.00$

Whether hospital staff adequately comply with isolation precautions

Yes

20

18.18

No

56

50.91

Partially

34
30.91 
TABLE 2. Distribution of Items Regarding Nurses' Compliance with Isolation Precautions ( $n=\| 10)$

I. I believe that nosocomial infections can be controlled by implementing isolation precautions.

2. I will be a strict follower of the continuous implementation of isolation precautions.

3. If the pathogenic microorganism is transmitted to the patient through more than one route, I apply isolation precautions together.

4. I wash my hands before contact with a patient.

5. Sometimes I do not use gloves during the care and treatment of the patient undergoing contact isolation.

6. I remove the gloves before leaving the patient's room.

7. I do not need to wash or scrub my hands when

I remove the gloves.

8. I wear a protective apron in the implementation of strict contact insulation.

9. I take care to change the protective mask when it is wet.

10. I provide the necessary barrier measures during

the transfer of the patient.

II. If the patient undergoing isolation is examined in another unit, I would warn the relevant unit supervisor to continue

to apply the isolation precautions.

12. I do not mind touching a wound of the patient with naked hands.

13. I do not allow the patient, to whom isolation precaution is applied, to walk outside his/her room.

14. I restrict visits of the patient who is isolated.

15. I ensure that patient toilets and the surfaces more frequently touched in the isolation room are cleaned more frequently than the surfaces less touched in the isolation room.

16. I take care that the medical waste formed in the isolation room is disposed of in accordance with the relevant rules.

17. I do not want to give care to the patient who is undergoing isolation because of the risk of infection.

18. I take care that the cleaning materials used in the insulation room are not used in other patient rooms.

Overall Average

\begin{tabular}{|c|c|c|c|c|c|c|c|c|c|c|c|}
\hline \multicolumn{2}{|c|}{ I definitely agree } & \multicolumn{2}{|c|}{ I agree } & \multicolumn{2}{|c|}{ No idea } & \multicolumn{2}{|c|}{ I disagree } & \multicolumn{2}{|c|}{$\begin{array}{l}\text { I deefinitely } \\
\text { disagree }\end{array}$} & \multirow[b]{2}{*}{$x^{-}$} & \multirow[b]{2}{*}{$\mathbf{s}$} \\
\hline $\mathbf{n}$ & $\%$ & $\mathbf{n}$ & $\%$ & $\mathbf{n}$ & $\%$ & $\mathbf{n}$ & $\%$ & $\mathbf{n}$ & $\%$ & & \\
\hline
\end{tabular}

\begin{tabular}{|c|c|c|c|c|c|c|c|c|c|c|c|}
\hline 65 & 59.09 & 31 & 28.18 & 1 & 0.91 & 1 & 0.91 & 12 & 10.91 & 4.24 & 1.26 \\
\hline 62 & 56.36 & 27 & 24.55 & 9 & 8.18 & 5 & 4.55 & 7 & 6.36 & 4.20 & 1.17 \\
\hline 68 & 61.82 & 23 & 20.91 & 7 & 6.36 & 5 & 4.55 & 7 & 6.36 & 4.27 & 1.17 \\
\hline 78 & 70.91 & 20 & 18.18 & 1 & 0.91 & 2 & 1.82 & 9 & 8.18 & 4.42 & 1.17 \\
\hline 10 & 9.09 & 20 & 18.18 & 7 & 6.36 & 26 & 23.64 & 47 & 42.73 & 2.27 & 1.41 \\
\hline 64 & 58.18 & 31 & 28.18 & 4 & 3.64 & 4 & 3.64 & 7 & 6.36 & 4.28 & 1.13 \\
\hline 9 & 8.18 & 2 & 1.82 & 10 & 9.09 & 30 & 27.27 & 59 & 53.64 & 1.84 & 1.19 \\
\hline 61 & 55.45 & 33 & 30.00 & 5 & 4.55 & 3 & 2.73 & 8 & 7.27 & 4.24 & 1.15 \\
\hline 71 & 64.55 & 24 & 21.82 & 3 & 2.73 & 4 & 3.64 & 8 & 7.27 & 4.33 & 1.17 \\
\hline 75 & 68.18 & 21 & 19.09 & 3 & 2.73 & 3 & 2.73 & 8 & 7.27 & 4.38 & 1.16 \\
\hline 75 & 68.18 & 23 & 20.91 & 4 & 3.64 & 3 & 2.73 & 5 & 4.55 & 4.45 & 1.02 \\
\hline 10 & 9.09 & 3 & 2.73 & 2 & 1.82 & II & 10.00 & 84 & 76.36 & 1.58 & 1.24 \\
\hline 60 & 54.55 & 29 & 26.36 & 5 & 4.55 & 5 & 4.55 & II & 10.00 & 4.11 & 1.29 \\
\hline 67 & 60.91 & 25 & 22.73 & 6 & 5.45 & 4 & 3.64 & 8 & 7.27 & 4.26 & 1.19 \\
\hline
\end{tabular}

$\begin{array}{llllllllllll}72 & 65.45 & 21 & 19.09 & 3 & 2.73 & 4 & 3.64 & 10 & 9.09 & 4.28 & 1.26\end{array}$

$\begin{array}{lllllllllll}65 & 59.09 & 24 & 21.82 & 7 & 6.36 & 6 & 5.45 & 8 & 7.27 & 4.20\end{array}$

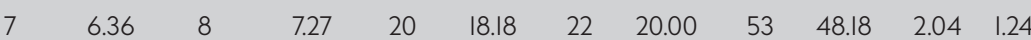

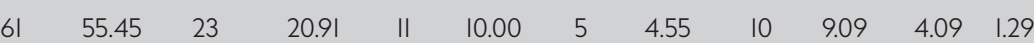
$3.75 \quad 1.01$

TABLE 3. The Relationship between Some Socio-Demographic Characteristics of Nurses and the Level of Their Compliance with Isolation Precautions $(n=110)$

\begin{tabular}{|c|c|c|c|c|c|c|}
\hline Some Socio-Demographic Characteristics & & n & $\overline{\mathbf{x}}$ & SD & $\mathrm{Z}, \mathrm{X}^{2}$ & $\mathbf{p}$ \\
\hline \multirow[t]{2}{*}{ Being trained on the isolation precautions taken for preventing HAls } & Yes & 104 & 76.81 & 14.99 & $Z=-2.442$ & $0.015^{*}$ \\
\hline & No & 6 & 62.50 & 15.64 & & \\
\hline Having adequate knowledge about HAls and isolotion precautions & No & 9 & 61.22 & 17.98 & & \\
\hline \multirow[t]{2}{*}{ Whether HAls can be controlled by giving relevant training on HAls and isolation precautions } & Yes & 75 & 78.71 & 13.64 & $X 2=14.058$ & $0.001^{* *}$ \\
\hline & Partially & 27 & 75.74 & 12.97 & & \\
\hline \multirow[t]{2}{*}{ Being immunized against HAls } & Yes & 37 & 70.78 & 18.14 & $Z=-2.008$ & $0.045^{*}$ \\
\hline & No & 73 & 78.68 & 12.98 & & \\
\hline
\end{tabular}


were not immunized against HAls was $78.68 \pm 12.98$, indicating a statistically significant difference between the mean scores $(p \leq .05)$ in favor of those who were not immunized (Table 3).

No statistically significant difference was found between the nurses' mean CIPS scores in terms of their age, sex, education level, employment status and professional experience, whether they believe in the importance of hand hygiene in preventing HAls, whether they think healthcare personnel directly or indirectly affect the development and spread of HAls, or whether they think hospital staff sufficiently comply with isolation precautions. These results may suggest that the aforementioned variables do not affect the level of nurse compliance with isolation precautions.

\section{DISCUSSION}

Most of the nurses received training on the isolation precautions taken to prevent HAls, and more than half of them received this training from an infection control nurse. This result is consistent with the results of studies conducted by Zencir et al. (15), Aytaç et al. (22), Erden et al. (20), Özden and Özveren (12), in which 82.7\%, 63.3\%, $79.0 \%$, and $78.4 \%$ of participating nurses, respectively, reported taking part in a training program related to HAls and isolation precautions. Other studies emphasize that the level of knowledge that healthcare professionals/nurses have on HAls and relevant isolation precautions play a decisive role in preventing HAls that prolong hospital stay and increase morbidity and mortality rates and medical costs $(3,4,6,16)$. In this respect, these results-which show that most nurses have participated in training programs on HAls and isolation precautions-are pleasing. In addition, the result indicating that the majority of the nurses received this training from an infection control nurse suggests that hospital staff training is given due emphasis in line with universal measures and nursing practices set by the CDC, and that infection control nurses are aware of their duties and responsibilities $(1,23)$.

Most nurses had knowledge about HAls. This result is consistent with the results of other studies conducted by Mankan and Kașı kçı (I0) and Aytaç et al. (22), in which 81.1\% and 78.1\% of participating nurses, respectively, correctly identified HAls and knew their types and the time intervals at which they occurred. When evaluated with the previous result, this result is considered satisfactory because the knowledge level of healthcare professionals and nurses plays a decisive role in preventing HAls.

More than half the nurses stated that HAls were controllable through relevant training. This result is consistent with the results found by Coopersmith et al. (4) regarding the effects of training programs on reducing HAls; in that study, the rate of $\mathrm{HAls}$ decreased by $66 \%$ as a result of relevant training given to healthcare professionals (39 nurses, I doctor, and 2 intensive care unit [ICU] personnel). This result suggests that nurses understood the role of training nurses in the prevention and control of HAls and were consciously aware of this issue.

In addition, the result that $66.36 \%$ of the nurses $(n=73)$ were not vaccinated against HAls, that only $33.64 \%(n=37)$ were immunized with anti-HBV vaccine, and that $43.24 \%(n=16)$ did not respond to the relevant question is consistent with the results of the study by Aytaç et al. (22), in which $90.5 \%$ of the nurses stated that receiving HBV vaccine was important to preventing HAls. These results suggest that nonvaccinated nurses do not have conscious awareness of protecting themselves against infections. Of the nurses, $79.09 \%(n=87)$ believed that healthcare personnel influenced the development and spread of HAls and $50.1 \%$ ( $n=56$ ) thought that hospital staff did not adequately comply with isolation precautions. These results suggest that nurses are aware of the importance and key role of healthcare personnel in the prevention of HAls.

The nurses' total mean CIPS score was $3.75 \pm 1.01$. This is a positive result, indicating that the nurses had a high level of compliance with isolation precautions, and parallels the results of many studies that used the CIPS and found that nurses had a high level of compliance with isolation precautions $(12,15,20)$. However, this result does not agree with the results of the study by Pettinger and Nettleman (9), in which the level of nurses' compliance with isolation precautions was found to be insufficient. Halcomb et al. (I7) reported that nurse failure to comply with isolation precautions negatively affected both nursing care and psychological and social lives of patients and their families. Accordingly, the results of this study also suggest that a high level of compliance of nurses with isolation precautions positively affects both nursing care and psychological and social lives of patients and their families.

No statistically significant difference was found in the levels of nurse compliance with isolation precautions in terms of their education level ( $P>$.05). However, Özden and Özveren (I2) stated that the education level of nurses did influence the level of their compliance with isolation precautions, reporting that nurses with a Bachelor's degree had a much higher mean compliance score than the nurses who graduated from a vocational health high school. Zencir et al. (I5) also found that the nurses' education level influenced the level of their compliance with isolation precautions, reporting that those with a Master's degree had a higher mean compliance score than those with a Bachelor's or Associate's degree and those who graduated from vocational health high schools. Similarly, this study found that the mean CIPS scores of the nurses with Bachelor's or postgradvate degrees were higher than the mean scores of the nurses with vocational health high school or Associate's degrees. The literature emphasizes that undergraduate education is very important in terms of informing health personnel and leading to positive behavioral changes (12). This result can be attributed to the fact that the level of knowledge and awareness of nurses increases as their level of education increases.

No statistically significant difference was found in the levels of nurse compliance with isolation precautions in terms of work experience $(P>$.05). However, the mean CIPS score of the nurses with $\geq 6$ years of work experience was higher than the mean scores of nurses with less experience. This result is consistent with the results of studies conducted by Zencir et al. (15) and Özden and Özveren (12), which reported that as nurses' work experience increased, so did the level of their compliance with isolation precautions. A study conducted in Nigeria found that nurses with professional experience of $\geq 10$ years had a high level of compliance with isolation precautions. ${ }^{24}$ This suggests that the length of professional experience and in-service training programs have a positive effect on the level of nurse compliance with isolation precautions taken to control HAls. The literature notes that professional experience and experience-induced learning reflect positively on the professional practices of nurses $(5,12)$. 
A statistically significant difference was found in the mean CIPS scores of nurses who received training on the isolation precautions taken to prevent HAls and those who did not receive such training. The difference favored those with the training $(P<.05)$. This result is consistent with those of a study by Helder et al. (25), in which the level of compliance with hand hygiene increased among health professionals who participated in a training program; this led to a decrease in HAls. The result is also in agreement with those of a study by Pekuslu et al. (26), in which the level of compliance with isolation precautions among doctors and nurses who received training on the issue was found to be higher than among those who did not receive that training. However, many other studies found no statistically significant relationship between the level of compliance with isolation precautions and the training received in this regard $(10,12,15,20,22)$. Training has a vital role in ensuring that healthcare professionals comply with isolation precautions. Jeffe et al. (27) found that training positively improved nurse knowledge and attitudes. In this context, periodically repeating the training on isolation precautions in a way that includes all healthcare professionals who provide healthcare services and putting into practice the solutions suggested to determine what factors are preventing compliance with isolation precautions may increase compliance with isolation precautions. The literature emphasizes support-via trainings, audits, and feedbackparticularly for nurses who comply with infection control measures as a way to increase the quality of healthcare given $(16,23)$.

There was a statistically significant difference between the mean CIPS scores of nurses who reported having adequate knowledge about HAls and isolation precautions and those who reported not having such knowledge $(P<.01)$. Considering that the majority of the nurses (94.55\%) who participated in our study were trained on HAls and isolation precautions, this result may be considered a satisfactory result supporting the fact that relevant training programs positively affect nurses' knowledge, attitudes, and behaviors regarding $\mathrm{HAls}$ and isolation precautions.

A statistically significant difference was found between the mean CIPS scores of the nurses who reported believing that HAls can be controlled through relevant training and isolation precautions and those who did not $(P<.0 \mathrm{l})$. This result is consistent with those of a study by Helder et al. (25), in which levels of compliance with hand hygiene increased among healthcare professionals who participated in a training program, thereby decreasing HAls. This result is also consistent with those of a study by Kanouff et al. (28), which reported that HAls in ICUs can be prevented through training and strict control. The result is also in agreement with those of a study by Coopersmith et al. (4), which asserted that a training program was found to be very effective in reducing HAls in surgical ICUs; the rate of HAls decreased by $66 \%$ as a result of relevant training given to healthcare professionals. Cetinkaya Șardan (29) concluded that hand hygiene and antiseptics were the most important measures controlling the spread of HAls. The result of this study suggests that training programs are key to preventing/controlling HAls.

There was no statistically significant difference between the mean CIPS scores of the nurses who reported believing in the importance of hand hygiene in preventing HAls and those who did not believe this ( $P>$.05). Özden and Özveren (I2) found that healthcare professionals received low mean scores on the patient safety, hand hygiene, and use of gloves subscales on the
CIPS. The CDC emphasizes the necessity of handwashing before and after providing care for each patient to prevent HAls (I). In addition, Boyce and Pittet (II) emphasized that poor hand hygiene-either washing or using an antiseptic hand rub-is a major contributor to infection. According to the results of this study, nurses' beliefs that hand hygiene is important for preventing HAls is considered a variable that does not affect the level of their compliance with isolation precautions. Furthermore, the effect of hand hygiene and related subjects/concepts should be investigated in detail through future qualitative studies that should be carried out with larger samples.

No statistically significant difference was found between the mean CIPS scores of nurses who reported believing that healthcare professionals directly or indirectly affect the development and spread of HAls and those who did not ( $p>.05$ ). Although this result suggests that nurses' belief that healthcare professionals directly or indirectly affect the development and spread of HAls is a variable that does not affect the level of their compliance with isolation precautions, different studies report that the attitudes and behaviors of healthcare professionals constitute the most important factor in the development of HAls. HAls are controllable and preventable. The failure of nurses and physicians to comply with all isolation precautions, including hand hygiene as a basic isolation precaution and other infection control measures, causes the proliferation of microorganisms and the spread of infections (II, I3, 30,3I). The transmission of microorganisms usually occurs during medical care and intervention. Nurses and physicians are expected to comply with necessary measures to control infection in the delivery of healthcare and to exercise due diligence during diagnosis, treatment, and care $(18,31,32)$. Nurses who are frequently in contact with patients to meet their care and treatment needs, as well as other healthcare professionals, have an important role in preventing the development and spread of HAls $(6,31,32)$.

In conclusion, the results of this study showed that nurses had a high level of compliance with the isolation precautions taken to prevent HAls. Given these results, the following advice is offered:

I. Increase the number of continuous education programs to encourage nurses and healthcare professionals to comply with infection control measures and isolation precautions at the highest level.

2. Create studies and activities to raise the awareness of all healthcare professionals about the importance of hand hygiene habits.

3. Ensure that all healthcare professionals cooperate in putting isolation compliance measures into practice.

4. Conduct further qualitative studies with larger samples.

This study has limitations. This study was conducted at only one university hospital in Nicosia. The results reflect only the practices of nurses at this hospital and cannot be generalized to all nurses.

Ethics Committee Approval: Ethics committee approval was received for this study from the ethics committee of Near East University (Approval Date/Number: YDU/20I7/47-4II).

Informed Consent: Informed consent was obtained from all individual participants included in the study. 
Peer-review: Externally peer-reviewed.

Author contributions: Concept - K.T.; Design - K.T., B.I.; Supervision - B.I.; Resource - K.T.; Materials - K.T., B.I.; Data Collection and/or Processing K.T.; Analysis and/or Interpretation - B.I., K.T.; Literature Search - K.T., B.I.; Writing - B.I., K.T.; Critical Reviews - B.I.

Conflict of Interest: Authors have no conflicts of interest to declare.

Financial Disclosure: The authors declared that this study has received no financial support.

\section{REFERENCES}

I. Centers for Disease Control and Prevention-CDC. Guideline for Isolation Precautions: Preventing Transmission of Infectious Agents in Healthcare Settings (2007). Int: 2019. Available from: URL: https:// www.cdc.gov/infectioncontrol/guidelines/isolation/index.html

2. World Health Organization (WHO). Guidelines For Hand Hygiene in Health Care - Global Patient Safety Challenge: Clean Care is Safer Care. Geneva:WHO Press, Int:2009. Available from:URL: hHtps://www.who.int/ gpsc/5may/tools/who_guidelines-handhygiene_summary.pdf

3. Allegranzi B, Bagheri Nejad S, Combescure C, Graafmans W, Attar $H$, Donaldson L, et al. Burden of endemic health-care-associated infection in developing countries: systematic review and meta-analysis. Lancet 20II; 377: 228-41. [Crossref]

4. Coopersmith CM, Rebmann TL, Zack JE, Ward MR, Corcoran RM, Schallom ME, et al. Effect of an education program on decreasing catheter-related bloodstream infections in the surgical intensive care unit. J Crit Care Med 2002; 30(I): 59-64. [Crossref]

5. Chan R, Molassiotis A, Chan E. Nurses knowledge of and compliance with universal precautions in an acute care hospital. Int J Nurs Stud 2002; 39(2): 157-63. [Crossref]

6. Chau J, Thompson D, Twinn S, Lee TFD, Pang WMS. An evaluation of hospital hand hygiene practice and glove use in Hong Kong. J Clin Nurs 20II; 20(9-I0): I319-28. [Crossref]

7. Klevens RM, Edwards JR, Richards CL, Horan TC, Gaynes RP, Pollock DA, et al. Estimating healthcare-associated infections and deaths in U.S. hospitals, 2002. Public Health Rep 2007; 122(2): 160-6. [Crossref]

8. Rosenthal VD, Guzman S, Safdar N. Reduction in nosocomial infection with improved hand hygiene in Instensive care units of a tertiary care hospital in Argentina. Am J Infect Control 2005; 33(7): 392-7. [Crossref]

9. Pettinger A, Nettleman MD. Epidemiology of Isolation precautions. Infect Control Hosp Epidemiol 1991; 12(5): 303-7. [Crossref]

10. Mankan T, Kașıkçı MK. The knowledge level of nurses related to prevention of hospital infections. Inonu University Journal of Health Sciences 2015; 4: II-6.

II. Boyce JM, Pittet D. Guideline for hand hygiene in health-care settings. recommendations of the healthcare infection control practices advisory committee and the HICPAC/SHEA/APIC/IDSA hand hygiene task force. society for healthcare epidemiology of America/ Association for professionals in infection control/Infectious diseases society of America. MMWR Recomm Rep 2002; 5I(RR-16): I-45.

12. Özden $D$, Özveren $H$. Determining the professional and organizational factors in nurses' compliance with isolation precautions. JAREN 2016; 2: 24-32. [Crossref]

13. Tayran N, Ulupınar S. Development of a scale study: validity and reliability of a scale compliance with isolation precautions. Florence Nightingale J Nurs 20II; 19: 89-98.

14. Valim MD, Marziale MHP, Richart-Martinez M, Sanjuan-Quiles A. Instrument for evaluating compliance with infection control practices and factors that affect it: An integrative review. J Clin Nurs 2014; 23(II-12): 1502-19. [Crossref]

15. Zencir G, Bayraktar D, Khorshid L. Nurses' compliance with isolation precautions worked in a public hospital. Journal of Ege University Nursing Faculty 2013; 29: 61-70.
16. Efstathiou G, Papastavrou E, Raftopoulos V, Merkouris A. Factors influencing nurses' compliance with standard precautions in order to avoid occupational exposure to microorganisms: a focus group study. BMC Nurs 20II; 10: I-12. [Crossref]

17. Halcomb EJ, Griffiths R, Fernandez R. The role of patient isolation and compliance with isolation practices in the control of nosocomial mrsa in acute care. Int J Evid Based Healthc 2008; 6(2): 206-24. [Crossref]

18. Gürsoy B. Economic analysis of hospital acquired infections: A case-control study. J Harran Unv Med F 2008; 5(I): I5-21.

19. Akyol DA. Hand hygiene among nurses in Turkey: opinions and practices. J Clin Nurs 2007; 16(3): 43I-7. [Crossref]

20. Erden S, Bayrak Kahraman B, Bulut B. Evaluation of compliance of physicians and nurses with isolation precautions in intensive care units. Gümüșhane University Journal of Health Sciences 2005; 4: 388-98.

21. Özdamar K. Bioistatistics with SPSS. Eskișehir: Kaan Bookstore; 2001.

22. Aytaç N, Naharcı H, Öztunç G. Knowledge about nozocomial infections of nurses working in intensive care in training and research hospitals in Adana. Journal of Adnan Menderes University Medical Faculty 2008; 9: 9-15.

23. Siegel JD, Rhinehart E, Jackson M, Chiarello L, the Healthcare Infection Control Practices Advisory Committee. 2007 Guideline for isolation precautions: preventing transmission of infectious agents in healthcare settings. Am J Infect Control 2007; 35(I0 Suppl 2): S65164. [Crossref]

24. Abdulrahem IS, Amodu MO, Saka MJ, Bolarinwa OA, Uthman MMB. Knowledge, awareness and compliance with standard precautions among health workers in North Eastern Nigeria. J Community Med Health Educ 20I2; I3I: 2-5.

25. Helder OK, Brug J, Looman CWN. The impact of an education program on hand hygine compliance and nosocomial infection incidence in an urban neonatal intensive care unit: An interventin study with before and after comparision. Int J Nurs Stud 20I0; 47(10): 1245-52. [Crossref]

26. Pekuslu S, Demirci H, Tașçıoğlu S, Tuna E. Bir devlet hastanesinde çalıșan hekim ve hemșirelerin izolasyon önlemlerine uyumlarının değerlendirilmesi. In: Umut B, Özlem Ö, editors. III. Uluslararası Sağlıkta Performans ve Kalite Kongresi Sözel Bildiriler Kitabı; 20II Nov 24-26; Ankara, Türkiye; 20II. pp. 5I-62.

27. Jeffe DB, Mutha S, Kim LE, Evanoff BA, Fraser VJ. Evaluation of a preclinicial, educational and skills-training program to improve students to use of blood and body fluid precautions: One -year follow-up. Prev Med 1999; 29(5): 365-73. [Crossref]

28. Kanouff AJ, DeHaven KD, Kaplan PD. Prevention of nosocomial infections in the intensive care unit. Crit Care Nurs Q 2008; 3I(4): 3028. [Crossref]

29. Cetinkaya Șardan Y. Infection control programs and infection control applications. Topçu A, Söyletir G, Doğanay M, editors. Infectious Diseases and Microbiology. İstanbul: Nobel Medical Press; 2008. p. 564-74.

30. Duerink DO, Farida H, Nagelkerke NJD, Wahyono H, Keuter M, Lestari ES, et al. Antimicrobial resistance in Indonesia: Prevalence and Prevention Study Group. Preventing nosocomial infections: Improving compliance with standard precautions in an Indonesian teaching hospital. J Hosp Infec 2006; 64(I): 36-43. [Crossref]

31. Kabir ASM, Akhter F, Sharmin M, Akhter K, Begum M, Saha A, Ahmed I. Knowledge, attitude and practice of staff nurses on hospital acquired infections in tertiary care Hospital of Dhaka city. Northern International Medical College Journal 2018; 10: 347-50. [Crossref]

32. Gruda A, Sopjani I. The knowledge, attitudes and practices of nurses toward management of hospital-acquired infections in the university clinical center of Kosovo. Mater Sociomed 2017; 29(2): 84-7. [Crossref] 